\title{
EFEITO DOS MATURADORES QUÍMICOS NA CULTURA DA CANA- DE-AÇÚCAR (Saccharum spp)
}

\author{
HIDA, José Nelson Tamura ${ }^{1}$ \\ SILVEIRA, João César Franco da ${ }^{1}$ \\ SEGATO, Silvelena Vanzolini ${ }^{2}$
}

Recebido em: 2009-06-09

Aprovado em: 2009-10-15

ISSUE DOI: $10.3738 / 1982.2278 .265$

\begin{abstract}
RESUMO: A maturação da cana-de-açúcar é um processo fisiológico que envolve a síntese dos açúcares nas folhas, translocação dos produtos formados e estocagem da sacarose no colmo. Os diferentes maturadores químicos diferem entre si não só na formulação, como também no tempo entre a aplicação e a colheita e nas condições climáticas exigidas. Esta revisão bibliográfica teve por objetivo fazer um levantamento do efeito dos maturadores químicos aplicados à cultura da cana-de-açúcar (Saccharum spp). A metodologia específica utilizada buscou a compreensão das publicações sobre o efeito dos maturadores químicos aplicados à cultura da cana-de-açúcar. Foram abordados resultados e recomendações sobre o uso e efeitos dos principais maturadores químicos aplicados à cultura da cana-de-açúcar, bem como o conceito de maturador e uso inibidores de florescimento. Concluiu-se que, os maturadores químicos aplicados à cultura da cana-de-açúcar possibilitaram melhor produtividade quando usados tecnicamente, conseguindo-se maior crescimento da planta e máximo acúmulo de sacarose.
\end{abstract}

Palavras-chave: Características tecnológicas. Maturação. Biomassa.

SUMMARY: The maturation of the sugarcane is a physiological process that involves the synthesis of sugars in the leaves, translocation of the products formed and storage of sucrose in the stem. The different chemical ripeners differ not only in formulating but also in the time between application and harvest and weather conditions required. This review aimed to make a survey of the effect of chemical ripeners in the sugarcane (Saccharum spp). The specific methodology used sought to understand the publications on the effect of chemicals applied to matured crop of sugarcane. Were matured addressed the various chemicals applied to the culture of sugarcane, and the effects of these, the concept of maturity, flowering and the use of inhibitors and the results and recommendations on the use. It was concluded that the chemicals ripeners in the sugarcane enabled improved productivity when used technically, combining increased plant growth and maximum accumulation of sucrose.

Keywords: Technological characteristics. Maturation. Biomass.

\section{INTRODUÇÃO}

A cana-de-açúcar, gramínea de clima tropical, tem sido cultivada em regiões de clima quente com solos férteis e bem drenados, com características climáticas compatíveis com as exigências técnicas da cultura. É principalmente cultivada como matéria-prima a ser

\footnotetext{
${ }^{1}$ Engenheiro agrônomo e Pós-graduando em Agroindústria Canavieira na Faculdade Dr. Francisco Maeda/FE.

${ }^{2}$ Doutorado em Agronomia pela Universidade Estadual Paulista Júlio de Mesquita Filho e professora de pósgraduação da FAFRAM/FE - Ituverava.
} 
fornecida, por esmagamento dos seus colmos para a extração do seu caldo, a um complexo industrial, com a finalidade de produzir açúcar, álcool, fermento e inúmeros outros derivados tanto para utilidades alimentícias como para a indústria química (CESNIK; MIOCQUE, 2004).

A cana-de-açúcar é uma cultura, que ganha destaque por gerar divisas e ser cultivada em vários países (UNICA, 2005).

O Agrianual (2008) apresenta o balanço mundial de açúcar (mil toneladas), destacando os maiores produtores mundiais na safra 2007/08, elencando o Brasil em primeiro lugar com 30.038.000 toneladas, a Índia com 28.790.000 toneladas, a União Européia com 16.665.000 toneladas, seguidos pela China, EUA, Tailândia, México e Austrália.

O estado de São Paulo é o maior produtor de cana-de-açúcar, possuindo 4,45 milhões de hectares disponíveis para colheita, representando $66 \%$ de toda a área cultivada na região centro-sul (PROJETO..., 2009).

A fim de atender a crescente demanda quer do mercado interno, como do mercado internacional pelo açúcar, álcool e subprodutos da cana-de-açúcar, torna-se necessário o provimento de matéria-prima de qualidade tecnológica à indústria sucroalcooleira. Daí, a importância em induzir a maturação da cana-de-açúcar pela aplicação de maturadores, conforme atesta Castro (2000), pois mesmo sob condições que favorecem a vegetação da cana-de-açúcar, também se pode induzir a maturação pela aplicação de maturadores.

Para Lavanholi et al (2002) e Almeida et al. (2003), maturadores, definidos como reguladores vegetais, são compostos químicos capazes de modificar a morfologia e a fisiologia da planta, que podem ocasionar modificações qualitativas e quantitativas na produção. Esses compostos possibilitam, entre outros benefícios, retardar ou inibir o desenvolvimento vegetativo, aumentar o teor de sacarose, tornar a maturação precoce e aumentar a produtividade de colmos e açúcar.

Esta revisão bibliográfica teve por objetivo fazer um levantamento do efeito dos maturadores químicos aplicados à cultura da cana-de-açúcar (Saccharum spp).

\section{REVISÃO DA LITERATURA}

\subsection{CONCEITO DE MATURAÇÃO}

A maturação da cana-de-açúcar é um processo fisiológico que envolve a síntese dos açúcares nas folhas, translocação dos produtos formados e estocagem da sacarose no colmo (FERNANDES, 1982). 
Segundo Fernandes (1984), a principal função dos maturadores químicos é a de interromper o desenvolvimento dos internódios e folhas em formação, induzindo a planta a transformar, com mais intensidade, os seus açúcares redutores em sacarose, armazenando-a no colmo. Os diferentes maturadores químicos diferem entre si não só na formulação, como também no modo de aplicação e nas condições climáticas exigidas.

O processo de maturação do ponto de vista agroindustrial é o estádio de desenvolvimento em que a cultura apresenta melhor produtividade quali-quantitativa de açúcares ou cuja produtividade agroindustrial e o resultado econômico encontram-se maximizados (MUTTON, 1993).

Conforme Castro (1992), um dos métodos adotados para acelerar e melhorar a maturação é o emprego dos maturadores químicos.

Conforme Deuber (1988), o processo de maturação da cana-de-açúcar ocorre naturalmente no início de maio na Região Sudeste do Brasil, atingindo seu clímax em outubro. As condições climáticas existentes, com gradativa queda da temperatura e a diminuição das precipitações pluviais, são as determinações neste processo. Para Caputo (2003), o processo de maturação da cana-de-açúcar tem sido estudado em diversos países, sendo de fundamental importância conhecer os atributos do caldo durante o desenvolvimento da planta, dada sua relação com a experimentação agronômica, avaliação rotineira do estádio de maturação ou pagamento da cana pelo teor de sacarose.

A maturação é considerada como um dos aspectos mais importantes na produção de cana-de-açúcar. A falta de cultivares com maturação precoce e produtiva podem ser contornadas empregando-se maturadores químicos, suprindo as usinas com cana madura todo ano. Os produtos tradicionalmente utilizados como maturadores de cana-de-açúcar, pertencem ao grupo dos inibidores de crescimento. No Brasil, os mais comumente aplicados são o glifosato, fluazifop-butil, sulfometuron-metil, etefon e o diquat (MORAIS NETTO, 2006).

\subsection{CONCEITO DE MATURADOR}

Conceitualmente, maturadores são produtos químicos que, em sua maioria, pertencem ao grupo dos reguladores de crescimento, que inibindo a elongação dos colmos sem afetar drasticamente a fotossíntese, favorecem a acumulação de açúcares nos tecidos de reserva (CASTRO, 1992).

Para Azevedo (1981), saltos nos rendimentos industriais são obtidos quando, a canade-açúcar é colhida no máximo de maturação. Os maturadores são produtos químicos que têm 
a propriedade de paralisar momentaneamente o desenvolvimento da cana induzindo a translocação e o armazenamento dos açúcares.

Os maturadores químicos além de aumentar o teor de sacarose, têm algumas vantagens interessantes e importantes, que de acordo com Fernandes (1984) são:

a) nas variedades que florescem, a aplicação dos maturadores inibe o florescimento. Uma vez que a inflorescência é a transformação da gema apical em panícula, e isto traz como consequência um consumo maior de energia (açúcares), não só para a formação da panícula, como também para a brotação das gemas laterais, tal inibição do florescimento é altamente providencial.

b) os maturadores químicos conferem uma resistência ao tombamento o que facilita sobremaneira o corte, diminuindo as perdas no campo e a quantidade de matéria estranha levada para a indústria.

c) devido ao enriquecimento do ponteiro e visto que as folhas da cana estão quase secas, ao se queimar o canavial a cana poderá ser enviada para a indústria sem se fazer o desponte, conferindo mais peso por hectare, mais açúcar e maior economicidade e rapidez no corte das mesmas.

Romero et al (1997) reforçam a afirmação de Fernandes (1984) ao citar que por meio do emprego dos maturadores químicos, procura-se modificar as condições naturais de maturação da cana-de-açúcar, objetivando promover acréscimos dos conteúdos de açúcares sem prejuízos para a produtividade dos colmos. Por outro lado, favorecem o acúmulo mais uniforme de açúcares nos entrenós da região apical, normalmente, imaturos. Alguns produtos podem acelerar o dessecamento das folhas, possibilitando realizar um desponte mais alto, o que resulta maior produção de colmos, reduzindo o conteúdo de matérias estranhas enviadas para a fábrica, além de melhorar a eficiência global da colheita.

Castro (1998) definiu que reguladores vegetais são substâncias sintéticas aplicadas exogenamente, que possuem ações similares aos grupos de hormônios conhecidos (auxinas, giberelinas, citocininas, retardadores, inibidores e etileno). Hormônios vegetais são compostos orgânicos, não nutrientes de ocorrência natural, produzidos na planta e que em baixas concentrações $\left(10^{-4} \mathrm{M}\right)$ promovem, inibem ou modificam processos morfológicos e fisiológicos do vegetal; consideram-se retardadores do crescimento as substâncias naturais ou sintéticas que possuem a capacidade de inibir o crescimento do meristema subapical.

As aplicações agrícolas de reguladores vegetais em algumas plantas cultivadas já atingiram estádios de evolução que exigem elevado nível técnico para alcançar maior produtividade. Essas culturas não mais possuem limitações de ordem nutricional e hídrica, além de serem protegidas adequadamente com defensivos. Nessas condições, a 
economicidade da utilização de tecnologia avançada tem elevado o emprego de reguladores vegetais que podem frequentemente, serem compensadores (NICKELL, 1988).

Leite (2005) acrescenta que nesse contexto, o emprego de maturadores químicos, definidos também como reguladores vegetais, na cultura da cana-de-açúcar, destaca-se como uma ferramenta importante.

Subiros (1990) afirma que maturadores são produtos aplicados com a finalidade de antecipar o processo de maturação, promover melhorias na qualidade da matéria-prima a ser processada, otimizar os resultados agroindustriais e econômicos e auxiliar no planejamento da safra. Visto que a maturação natural, em início de safra, pode ser deficiente, mesmo em variedades precoces, a aplicação de maturadores em cana-de-açúcar deve objetivar a indução da maturação durante períodos de baixa concentração de sacarose. $\mathrm{O}$ uso de reguladores vegetais deve ser uma prática a ser realizada em curto prazo, para ser substituída, posteriormente, por um programa de manejo de variedades que amadureçam nas épocas desejadas, obtendo-se assim rendimento aceitável durante os períodos críticos da safra.

Segundo Deuber (1986), em diversas regiões do mundo, em que as condições climáticas não são favoráveis, têm sido pesquisados produtos químicos que visam antecipar o processo de maturação da cana-de-açúcar. Produtos como o 2,4 D, ácido giberélico, Embark (mefluidide), Polaris (glifosato), Polado (glifosato), e Ethrel, foram estudados, mas o seu uso está muito restrito. Nas condições do Sudeste brasileiro, também foram feitas diversas tentativas, mas de modo geral, com muito pouco proveito ou retorno econômico, devido à dificuldade de apressar a maturação natural que aqui ocorre. O objetivo principal dos maturadores segundo esse mesmo autor é melhorar as condições de maturação no início do ciclo, nos meses de abril a junho.

Os maturadores são compostos que se enquadram no grupo dos reguladores de crescimento artificiais ou químicos. A utilização desses compostos abriu uma perspectiva no que diz respeito à antecipação da maturação nos meses iniciais da safra (DEUBER, 1988).

Para Gera (1994) os maturadores além de antecipar a maturação e evitar o florescimento são uma importante "ferramenta" na indução do aumento no teor de açúcares redutores totais, contribuindo para a melhoria da qualidade tecnológica da cana-de-açúcar.

As variedades diferem quanto às reações de fitotoxicidade que apresentam ao uso de produtos químicos mesmo quando submetidas às mesmas condições de tratamento. Conforme Cana do plantio à colheita (1985), no que concerne aos fenômenos de causas e efeitos da atividade do amadurecedor, no aspecto de toxicidade, dois pontos devem ser considerados:

a) sua influência sobre a clorofila das folhas e;

b) a intensidade dessa influência em função do comportamento varietal e das 
condições de aplicação (tipo de produto, dosagem, estádio da planta, horário de trabalho, etc.).

Segundo Cana do plantio à colheita (1985), são indispensáveis conhecimentos básicos, calçados na experimentação de campo, somente obtidos através de análises e avaliações por quem esteja devidamente capacitado à interpretação das observações colhidas.

\subsection{FLORESCIMENTO E O USO DE INIBIDORES}

O processo de florescimento implica em alterações morfológicas e fisiológicas no vegetal e, na cana-de-açúcar, tem sido considerado prejudicial ao acúmulo de sacarose, uma vez que a formação da flor drena considerável quantidade de sacarose, o que acarreta prejuízos à qualidade da matéria-prima fornecida à indústria sucroalcooleira. O chochamento (ou isoporização) tem início com a ocorrência do processo de florescimento e se caracteriza pelo secamento do interior do colmo e perda de peso final, oriunda da redução do volume de caldo. A depender da variedade e da condição ambiental à que ela está submetida, a intensidade dos processos é variável, bem como a intensidade dos problemas advindos desses fenômenos (SALATA; FERREIRA, 1977; DEUBER, 1988). Entretanto, segundo os mesmos autores, a ocorrência da brotação lateral pode implicar a queda da qualidade tecnológica dos colmos, uma vez que a formação desses brotos tardios mobiliza considerável quantidade de energia da planta, em contrapartida ao processo de acúmulo de sacarose.

De acordo com Deuber (1986), a idéia de que o florescimento da cana-de-açúcar causa, desde o início, queda na produção ou acúmulo de açúcar, não está comprovada experimentalmente. $\mathrm{O}$ que a pesquisa tem mostrado é que os teores de sacarose continuam a crescer, juntamente com a formação da flor durante vários meses.

Conforme Deuber (1988), diversos reguladores têm sido utilizados com a finalidade de inibir o florescimento ou de antecipar a maturação. Segundo o autor, o ethephon vem sendo utilizado para inibir o florescimento em muitas usinas e destilarias. Os resultados obtidos, em geral no meio da safra, não tem apresentado retornos econômicos, mesmo com total supressão do florescimento.

Em experimento para verificar o efeito da época de aplicação de inibidores de florescimento na cana, Fernandes (1997) verificou que o Ethrel (ethephon) proporcionou um aumento no peso dos colmos. A aplicação de Ethrel, na dosagem (2.000 mL p.c por ha), não interferiu nos valores de densidade obtidos e não se mostrou eficiente inibidor, pois não diferiu do imazapyr (200 mL p.c. ha ${ }^{-1}$.).

Para verificar os resultados da aplicação de ethephon em cana-de-açúcar, nas usinas da região de Ribeirão Preto, SP, foi realizado um experimento por Gera (1994) que constatou 
que o alto índice de florescimento que algumas variedades de cana-de-açúcar apresentam é balizado por fatores climáticos, prejudicando a sua qualidade. Para o autor, o ethephon 0,24 Kg. $L^{-1}$ é uma "ferramenta" indispensável para antecipar a maturação e evitar o florescimento. Segundo o mesmo autor, para as condições da região de Ribeirão Preto, SP, a melhor época para a aplicação de ethephon é de 20 de fevereiro a 20 de março, com dosagens variando de 1,5 a 2,0 L.ha ${ }^{-1}$ dando excelentes resultados, permitindo iniciar a safra mais cedo com a matéria-prima de boa qualidade. Entretanto, deve-se observar antes da aplicação se a planta não passa por nenhum tipo de estresse, pois tal fato seria prejudicial. Assim, para Almeida et al. (2003) o ethephon na dose de 480 g.ha ${ }^{-1}$ manteve a curva de maturação semelhante à testemunha, não provocando resposta de maturação antecipada, provavelmente em função das condições climáticas favoráveis à maturação normal da cana, uma vez que a mesma já se encontra em condições de estresse ambiental.

Fernandes (1997), ao estudar o efeito do Ethrel em diferentes variedades de cana-deaçúcar, concluiu que este produto, na dosagem de $2 \mathrm{~L}_{\text {p.c. }} \mathrm{ha}^{-1}$., aplicados nos dias 21 a 26 de março, inibiu o florescimento e isoporação na variedade SP70-1143 e nas RB72-454 e RB785148 não ocorreu florescimento nas testemunhas e, no geral, todas as variedades se beneficiaram do uso de Ethrel.

\subsection{PRINCIPAIS MATURADORES: RESULTADOS E RECOMENDAÇÕES}

Conforme Morais Netto (2006), os novos cultivares obtidos pelos programas de melhoramento, a utilização de controle biológico de pragas e doenças e outros tratamentos fitossanitários, a aplicação de herbicidas, o uso de reguladores vegetais e maturadores, dentre outras práticas agronômicas, têm levado a aumentos significativos na produtividade. Para o autor, no entanto, diversos estádios do ciclo da cultura têm sido identificados como fases limitantes de produção. Destaca os estádios que têm sido pesquisados com variados graus de sucesso, incluindo emergência, perfilhamento, crescimento, florescimento, maturação e senescência.

Segundo o autor, a compreensão dos fenômenos fisiológicos que ocorrem em cada uma dessas etapas é fundamental para que práticas racionais de manejo da cultura sejam recomendadas.

Dentre as alternativas para os incrementos na produção, tanto quantitativos como qualitativos, pode-se citar os reguladores vegetais e os maturadores da cana-de-açúcar. Assim os aminoácidos, maturadores e inibidores de florescimento são produtos que, embora 
apresentem custo inicial elevado, resultam em aumento de produtividade garantindo um bom retorno econômico (MORAIS NETTO, 2006).

De acordo com Nascimento; Gheller (1998) os principais produtos utilizados como maturadores no mercado são: Ethrel (Ethefon), regulador de crescimento, aumenta o teor de sacarose, reduz isoporização e inibe o florescimento. $\mathrm{O}$ produto comercial Roundup (glyfosate), ao contrário do anterior, é um inibidor de crescimento podendo destruir a gema apical da planta, cessando assim, a formação de novos entrenós. Por esse fato a colheita deve ser realizada até 4-5 semanas após aplicação, a partir do qual irá existir intensa brotação lateral, prejudicial à qualidade da matéria-prima. Inibe o florescimento, reduz a isoporização e aumenta o teor de sacarose. Já o produto Moddus (etil-trinexapac) reduz o nível de giberelina ativa, diminuindo a ação de promotores de crescimento, sem afetar, porém, o processo de fotossíntese e a integridade da gema apical. Aumenta o teor de sacarose e inibe o florescimento (NASCIMENTO; GHELLER, 1998).

Para Morais Netto (2006) os maturadores mais usados na cultura da cana-de-açúcar no Brasil são: o ethefon, o glifosate, diquat, sulfometuron-metil e o fluazifop-butil.

Para indução artificial da maturação, o glifosato paralisa o crescimento da altura e modifica a partição dos fotoassimilados, deslocando para o acúmulo de sacarose. O modo de ação desse maturador (utilização de dosagens reduzidas) segundo DUKE et al. (2003) é a inibição da via metabólica do ácido chiquímico, fundamental para a produção de aminoácidos aromáticos, bem como a de compostos secundários.

De acordo com Galli (1993) o glifosato é uma ótima opção técnica e econômica para flexibilizar o manejo de corte. Este maturador aumenta o teor de sacarose durante todo o período de safra, permite manejar o comportamento das variedades, flexibiliza o manejo de corte, melhora a qualidade da matéria-prima para a indústria, paralisa o florescimento, otimiza o potencial das variedades e a margem de contribuição agrícola e industrial e é a alternativa mais econômica e eficiente para aumentar a rentabilidade de álcool ou açúcar por área.

Quanto aos maturadores químicos, Morais Netto (2006) afirma que o glifosato, (fosfonometil) tem sido usado nas doses 0,3 a $0,5 \mathrm{~L}$ p.c. $\mathrm{ha}^{-1}$, tendo por características, translocação apo-simplástica (floema) nas folhas, meristemas aéreos e subterrâneos, não é metabolizado pelas plantas; atua sobre a atividade enzimática responsável pela formação de aminoácidos e outras substâncias endógenas. Causa na fotossíntese, inibição na síntese de fenóis e ácidos nucléicos; reduz a respiração e estimula a produção de etileno. Pelo fato do glifosato ser um herbicida sistêmico, auxilia na maturação da cana, ao provocar a morte da gema apical, quando aplicado em sub-dosagem. Mas se por algum erro de planejamento, a área tratada ultrapassar 50 dias para ser colhida, a brotação da soqueira e as produções 
subsequentes podem ser afetadas. Por apresentar um dos menores custos de mercado, o glifosato está sendo muito utilizado em conjunto com outro regulador químico, empregando metade de sua dosagem (MORAIS NETTO, 2006).

Estudos realizados na Fazenda Algodoal pertencente à Usina Santa Lídia, mostrou que o glifosato, principalmente na dosagem de 0,25 L ha.-1 foi o tratamento que apresentou melhor performance, promovendo maiores influências sobre as características tecnológicas (Brix \% Caldo, Pol \% caldo, Pureza do caldo, Pol \% cana, AT\% cana, Ágio/deságio e ATR $\left(\mathrm{kg} \mathrm{t}^{-1}\right)$, sem caracterizar redução no crescimento dos colmos, proporcionando 2 semanas de antecipação na colheita com melhor efeito entre a $4^{\mathrm{a}}$ e $6^{\mathrm{a}}$ semana após a aplicação segundo Sant'anna (1991) Legendre; Finger (1987) citado por Patrezze (1994) estudando a resposta de 7 variedades de cana-de-açúcar ao emprego do glifosato, constataram que houve um aumento do teor de açúcar contido nos colmos. Devido a um efeito negativo do glifosato sobre o peso dos colmos, a recuperação desse açúcar foi prejudicada em alguns cultivares. Constataram também que condições climáticas, no que se refere aos parâmetros chuva e temperatura, afetaram a resposta da cana-de-açúcar ao maturador. A máxima resposta foi observada em condições de maior temperatura e umidade.

Apesar dos efeitos positivos, alguns reguladores de crescimento utilizados como maturadores podem ter efeito colateral, prejudicando a cana-soca seguinte. Segundo Julien (1997), de dez experimentos realizados com o produto comercial Polaris (glifosate), em quatro deles ocorreu uma pobre brotação da cana-soca. O mesmo autor salientou que fatores como o ambiente, o estádio de desenvolvimento da cultura na época de aplicação do produto químico, os intervalos entre a data de aplicação e a colheita e o uso de substâncias de baixa deriva (Nalco-trol) podem afetar a rebrota.

Para as condições brasileiras, usa-se um regulador vegetal do grupo do etileno, como estimulante da maturação da cana-de-açúcar. O etefon 720 tem sido aplicado 60 dias antes de colher, na dosagem de 0,67 L p.c./ha. Possui na fórmula o ácido fosfônico e as seguintes características: perde estabilidade em contato com tecido vegetal ( $\mathrm{pH} 3,0-3,5)$ liberando etileno gasoso, liga-se a um receptor protéico (hidroxiprolina) associado à membrana plasmática, afetando a atividade da ATPase e alterando a permeabilidade celular, possibilitando reações que levam a senescência (antecipa a maturação). Retarda na época da aplicação, o crescimento do entrenó por bloquear diretamente o metabolismo do DNA no meristema subapical. Pode alterar o transporte e o metabolismo de auxinas (promotoras de crescimento); aplicado antes da iniciação floral (fevereiro-março), inibe a formação da inflorescência e consequentemente o volume de parênquima sem caldo (isopor); estimulando a emergência de brotação da soqueira (MORAIS NETTO, 2006). 
Afirma Ribeiro Neto (2002), que a aplicação de maturadores químicos pode mostrar resultados promissores quando usados sob condições climáticas que não favorecem o amadurecimento natural da cana-de-açúcar. O ethephon (Ethrel), ácido (2 - cloroetil) fosfônico é um produto químico que libera etileno em contato com o tecido vegetal, o mecanismo de ação do etileno envolve sua ligação a um receptor protéico através de um processo reversível.

Pontin (1994) reforça a afirmação de Ribeiro Neto (2002), ao citar que o ethephon, tem-se revelado eficiente maturador da cana-de-açúcar, não ocasionando a morte da gema apical.

Castro et al. (2002), em experimentos realizados em Santa Bárbara D’Oeste, SP, constataram que a aplicação de Ethrel 2 L.ha ${ }^{-1}$ em 08 de março aumentou os teores de pol \% cana do cultivar SP70-1143 aos 20, 41 e 62 dias após tratamento (DAT); que o Ethrel aplicado em 08 de março reduziu a isoporização aos 63 e 94 DAT; que não afetou o número médio de entrenós por colmo e que não afetou o peso da produção da cana-de-açúcar. Já a pulverização com Ethrel 2 L.ha $^{-1}$ em 18 de abril incrementou o pol \% cana de SP70-1143 aos 21 DAT e reduziu o número de entrenós por colmo aos 52 DAT.

Martins (1993) em citação de Ribeiro Neto (2002) observou aumentos significativos de pol \% cana na variedade SP70-1143, com a aplicação de Ethrel 2,0 L.ha ${ }^{-1}$. Para os valores de açúcar total recuperado (ATR) da cana-de-açúcar não foram notadas diferenças significativas ou tendências de aumento com o uso do ethephon.

Também Castro (1983), salientou que pesquisas com maturadores têm demonstrado que o ethephon apresenta resultados promissores em cana-de-açúcar.

Sant'Anna (1991) observou na região de Sertãozinho, SP, com aplicação de Ethrel, valores maiores de Brix e Pol, doze semanas após a aplicação. Elevações da pol \% cana no início da safra têm sido frequentes tanto em áreas experimentais como nas áreas de plantio comercial. Esse fato levou Sant' Anna (1991) a intensificar os estudos do uso de ethephon com o objetivo de antecipar a maturação. Em resultados de pol \% cana, obtidos com três diferentes variedades de cana-de-açúcar, com seis meses após o segundo corte, nas quais se aplicaram as doses de 0,48 e $0,72 \mathrm{~kg} \cdot \mathrm{ha}^{-1}$ de ethephon, no dia 22 de fevereiro, pode-se verificar que, de modo geral, houve resposta para pol \% cana aos 60 dias após a aplicação, para todas as variedades. A SP70-1284 mostrou ser a mais sensível, mantendo a diferença por todo o resto do ciclo. A SP70-1143 apresentou sensibilidade intermediária e a IAC52-150 foi a menos sensível, em termos de duração do efeito.

Caputo et al. (2007) visando determinar a resposta de genótipos de cana-de-açúcar à aplicação de dois reguladores vegetais sobre o acúmulo de sacarose, a produtividade e o 
florescimento realizaram um ensaio em março de 2004 próximo a Jaú, SP. O delineamento experimental foi o de blocos casualizados, em parcelas subdivididas, com quatro repetições, constituído pela combinação de sete genótipos (IAC87-3396, IAC87-3410, IAC89-3124, IAC91-2195, IAC91-5155, PO88-62 e SP80-1842) e de três manejos de condução da maturação: sulfometuron-metil $\left(15 \mathrm{~g}\right.$ i.a. $\left.\cdot \mathrm{ha}^{-1}\right)$, etefon $\left(480 \mathrm{~g}\right.$ i.a. $\left.\cdot \mathrm{ha}^{-1}\right)$ e testemunha. A pol na cana foi determinada aos 0, 21, 42, 63, 84, 105 e 126 dias após a aplicação (DAA), além dos atributos florescimento, "isoporização", produtividade de colmos e de açúcar aos 126 DAA. Observou-se que, para a maioria dos genótipos, o emprego dos maturadores antecipou a colheita em 21 dias em relação à testemunha, sendo o etefon indicado para colheita entre $42 \mathrm{e}$ 84 DAA, e o sulfometuron-metil para o período entre 105 e 126 DAA. Os dois produtos controlaram o florescimento. Para a maioria dos genótipos, os maturadores não afetaram a produtividade de colmos. O sulfometuron-metil e o etefon aumentaram a produtividade de açúcar do genótipo IAC89-3124. O IAC91-2195 apresentou produtividade de açúcar maior com a aplicação de etefon. A produtividade de açúcar foi menor na SP80-1842 com o emprego de sulfometuron-metil.

Almeida et al. (2003) relataram que o sulfometuron-methyl foi eficiente como maturador e antecipou em 15 dias a colheita da cana-de-açúcar, inclusive tendo o pico de maturação antecipado em relação aos outros maturadores. Embora tenha promovido injúria à cana, esta se recuperou, não afetando altura, tamanho, diâmetro, peso de 10 colmos e a produção de colmos. O sulfometuron-methyl $\left(20 \mathrm{~g} / \mathrm{ha}^{-1}\right)$, assim como o ethephon $\left(15 \mathrm{~g} / \mathrm{ha}^{-1}\right)$, não promoveu a morte da região apical nas doses utilizadas como maturador.

Com objetivo de avaliar as variáveis químico-tecnológicas e acompanhar o efeito dos maturadores químicos na cultura de cana-de-açúcar no final de safra, utilizando a variedade RB72454 Viana et al. (2007) realizou um experimento. O delineamento experimental utilizado foi em blocos casualizados, com parcelas subdivididas, sendo os tratamentos principais: testemunha, glifosato aplicado nas dosagens de $0,4 \mathrm{~L}$ de produto comercial por hectare $\left(\right.$ p.c.ha ${ }^{-1}$ ), 3,0 L de p.c. $\mathrm{ha}^{-1}, 6,0 \mathrm{~L}$ de p.c. ha ${ }^{-1}$ e sulfometuronmetil aplicado na dosagem de $20 \mathrm{~g} / \mathrm{ha}^{-1}$. Os tratamentos secundários constituíram-se das épocas de amostragens: respectivamente aos 0 dias após a aplicação (d.a.a.), 11 d.a.a., 18 d.a.a., 28 d.a.a., 35 d.a.a. e 43 d.a.a. A aplicação de maturadores químicos promoveu um incremento significativo sobre as características tecnológicas da planta como: Brix (\%) cana, Pol (\%) cana, TPH, Fibra (\%) cana ao longo das épocas de colheita avaliadas, tendo um destaque para o glifosate $0,4 \mathrm{~L}$ de p.c ha ${ }^{-1}$ e sulfometuron-metil 20g.ha ${ }^{-1}$. A precipitação ocorrida ao longo do período de amostragem aos 43 d.a.a. pode ter causado a retomada do metabolismo de crescimento da cana-de-açúcar, favorecendo o aumento de compostos fenólicos na planta. Em relação às 
épocas, os melhores resultados observados ocorreram na $4^{\mathrm{a}}$ época de amostragem, aos 28 dias após a aplicação para o Brix \% cana, Pol \% cana, TPH. O uso de maturadores químicos na cultura não afetou significativamente algumas características tecnológicas importantes para a qualidade da matéria prima na indústria como: compostos fenólicos, acidez total, acidez volátil.

Com relação ao uso do maturador químico curavial (sulfometuron metil), Morais Netto (2006) pondera que tem um custo acessível, porém não demonstra um resultado tão eficaz em relação aos outros maturadores, sendo um produto interessante para ser usado em mistura principalmente com o glifosato.

Caputo et al. (2008) com objetivo de avaliar a resposta de sete genótipos de cana-deaçúcar à aplicação de dois reguladores vegetais quanto à qualidade da matéria-prima, utilizando-se do mesmo ensaio citado em Caputo et al. (2007) avaliaram a qualidade tecnológica determinada pelos atributos: sólidos solúveis totais $\left({ }^{\circ} \mathrm{Brix}\right)$ no caldo, sacarose (pol $\%$ ) no caldo, pureza do caldo, fibra da cana, açúcares redutores (AR) do caldo e açúcar total recuperável (ATR) no caldo aos 0, 21, 42, 63, 84, 105 e 126 dias após a aplicação (DAA) dos maturadores. Observou-se que os genótipos responderam diferentemente ao emprego dos maturadores etefon e sulfometuron-metil. O genótipo PO88-62 foi mais responsivo ao sulfometuron-metil; IAC87-3396, IAC87-3410, IAC91-5155 e SP80-1842 ao etefon, e IAC89-3124 e IAC91-2195 responderam a ambos.

Silva et al. (2007) em pesquisa que objetivou avaliar o efeito residual de dois reguladores vegetais, aplicados antes da colheita, na brotação da cana-soca e na produtividade de três genótipos de cana-de-açúcar realizaram um ensaio na região de Jaú (SP). O delineamento experimental foi o de blocos casualizados, em parcelas subdivididas, com quatro repetições, constituído pela combinação dos genótipos IAC87-3396, IAC91-2195 e IAC91-5155, e de três formas de manejos da cultura: sulfometuronmetil, $20 \mathrm{~g}$ ha-1; etefon, 480 g i.a. ha-1 e testemunha. A aplicação dos reguladores vegetais ocorreu 126 dias antes do corte das touceiras. Foram realizadas avaliações para quantificar o número de perfilhos m-1 aos $0,90,180,270$ e 360 dias após o corte; a porcentagem de colmos por metro final em relação à inicial; a massa de 10 colmos, o comprimento e o diâmetro médios dos colmos; a pol e a fibra \% cana, os açúcares redutores e total recuperável, e a produtividade de colmos e de açúcar. Concluiu-se que houve efeito estimulante na emergência do perfilhamento até seis meses após o corte. O etefon promoveu maiores produtividades de colmos e de açúcar. Houve diferenças entre genótipos quanto à resposta do comprimento de colmos na cana-soca em relação aos reguladores vegetais. Não houve efeito sobre a qualidade tecnológica da cana-deaçúcar na cana-soca seguinte. 
Para Morais Netto (2006), o diquat, o glifosato e o fluazifop-butil são inibidores que podem promover em curto período de tempo (30 dias), uma grande alocação de sacarose para o colmo. São de baixo custo, mas devem ser aplicados com cuidado, para evitar a sobreposição e danos no canavial, assim como bem planejada evitando problemas de inversão da sacarose no campo.

Zillo (2003) avaliou, em experimento realizado em usina na região de Ribeirão Preto, SP, os efeitos dos maturadores ethyltrinexapac, Aminolon Maduracion e glifosafe na variedade SP80-1816, constatando que o ethyltrinexapac contribuiu para a melhoria dos parâmetros tecnológicos da cana aos 44 e 65 dias após aplicação (d.a.a.), sendo superado apenas pelo glifosate.

Segundo Morais Netto (2006) experimentos no centro-sul, demonstram a eficiência do ethrel (etefon) quando aplicado precocemente e do glifosato, curavial, moddus e fusilade em aplicação tardia, para a colheita e acúmulo de sacarose na cana-de-açúcar. Podem ser utilizados se necessário durante todo o ano. No centro-sul os períodos que proporcionam retornos melhores e mais econômicos, é o começo da safra (abril a junho), onde o acréscimo de Açúcar Total Recuperável (ATR), é em torno de $8,5 \mathrm{Kg} / \mathrm{t}$. Também ao final de safra (outubro e novembro) é utilizado com intuito de evitar uma queda muito drástica de ATR, conseguindo-se valores em torno de $4,0 \mathrm{Kg} / \mathrm{t}$ em relação à testemunha. Adequando-se os reguladores para as condições ideais de uso, têm-se resultados financeiros e de qualidade do canavial mais significativos.

Ainda Morais Netto (2006) orienta que outra forma para melhorar a maturação da cana-de-açúcar, na colheita mecanizada crua, seria retirar a matéria seca, ou seja, as suas folhas, pois estas absorvem o caldo no momento de sua extração na usina, gerando uma perda. Um dos métodos testados para a remoção da folhagem seria através da desfolhação química. Testes com numerosos herbicidas mostraram que o paraquat e o diquat são eficientes agentes dessecantes ou desfolhantes, da cana-de-açúcar. As vantagens desses herbicidas estariam na: baixa toxicidade ao homem, solubilidade em água, rápida absorção e inativação em contato com o solo. Em testes realizados em usina na região de Ribeirão Preto, SP, a aplicação de paraquat (0,3 a 0,5 $\mathrm{Kg}$ do ingrediente ativo (i.a.) por ha) não afetou a qualidade dos colmos, quando a colheita foi realizada até os 15 dias após a pulverização.

Stupiello (1982), citado por Ribeiro Neto (2002) afirma que um melhor aproveitamento agroindustrial de um canavial poderá ser conseguido através da colheita da matéria-prima no estado de maturação. Do ponto de vista agrícola pode-se obter melhor produtividade quando o processo de maturação é seguido adequadamente, conseguindo-se maior crescimento da planta e máximo acúmulo de sacarose. A maior produtividade de 
colmos é obtida pelo desenvolvimento que ocorre durante a maturação, embora com taxa de crescimento mínima, e pelo menor desponte dos colmos maduros, cujo teor de sacarose nos internódios da ponta em estágio adiantado de maturação tende a se igualar a do colmo, podendo ser maior do que este último, quando a planta inicia novo ciclo vegetativo. A maturação como um processo fisiológico é afetado por vários fatores naturais, como a própria variedade, condições climáticas, tipo de solo e tratos culturais.

\section{CONSIDERAÇÕES FINAIS}

Pelo presente trabalho concluiu-se que, os maturadores químicos aplicados à cultura da cana-de-açúcar, interromperam o desenvolvimento dos internódios e folhas em formação, induzindo a planta a transformar, com mais intensidade, os seus açúcares redutores em sacarose, armazenando-a no colmo; induziram a translocação e o armazenamento dos açúcares, obtendo melhor produtividade quando aplicado observado parâmetros técnicos, tais como: dosagem, época de aplicação, intervalo entre aplicação e colheita, condições climáticas, genótipo entre outros, conseguindo-se assim maior crescimento da planta e máximo acúmulo de sacarose.

Observou-se que o principal efeito dos maturadores é o de alocar maior quantidade de sacarose aos colmos. É importante acompanhar o crescimento da cana para saber quando aplicar o produto visando não prejudicar o ganho em massa. A época de colheita após a aplicação é variável, sobretudo em função do produto aplicado. A resposta do maturador difere entre os genótipos. O clima, principalmente a precipitação e a temperatura, interfere na maior ou menor resposta dessa classe de produtos. É possível inibir o florescimento com uso de maturadores na época indutiva. As dosagens e demais tecnologias devem ser verificadas procurando melhor relação custo benefício.

\section{REFERÊNCIAS}

AGRIANUAL 2008: anuário da agricultura brasileira. São Paulo: IFNP, 2008. 236p.

ALMEIDA, J. C. V. de et al. Eficiência agronômica de sulfometuron-methyl como maturador na cultura da cana-de-açúcar (Isaccharum spp). Stab Açúcar, Álcool e Subprodutos. Piracicaba: Sociedade dos Técnicos Açucareiros e Alcooleiros do Brasil, v.21, n.3., 2003.

AZEVEDO, H. J. Fisiologia da cana-de-açúcar. Araras: Programa Nacional de Melhoramento da Cana-de-açúcar, 1981. 108p. (Apostila)

CANA do plantio à colheita. São Paulo: Quimbrasil, 1985. 41p. 
CAPUTO, M.M. Efeito do tombamento nas características tecnológicas e biométricas de variedades de cana-de-açúcar. 2003. 63f. Monografia (Trabalho de graduação em Agronomia) - Faculdade de Ciências Agrárias e Veterinárias - UNESP. Jaboticabal.

CAPUTO, M.M. et al. Acúmulo de sacarose, produtividade e florescimento de cana-de-açúcar sob reguladores vegetais., Interciencia. v.32, n.12, p.834-840, 2007.

CAPUTO, M.M. et al. Resposta de genótipos de cana-de-açúcar à aplicação de indutores de maturação. Bragantia, Campinas, v.67, n.1, p.15-23, 2008.

CASTRO, P.R.C. Reguladores vegetais: perspectivas de aplicação em cana-de-açúcar. Revista Stab - Tecnologia/Pesquisa. Piracicaba: ESALQ, p.26-28. 1983.

CASTRO, P.R.C. Fisiologia da cana-de-açúcar. In: ENCONTRO DE CANA-DE-AÇÚCAR, 1992, São Paulo. Anais... São Paulo, 1992. p.5-8.

CASTRO, P.R.C. Utilização de reguladores de vegetais na fruticultura, na olericultura e em plantas ornamentais. Piracicaba: DIBID/ESALQ/USP, 1998. 91p. (Boletim Série Produtor Rural)

CASTRO, P.R.C. Utilização de reguladores vegetais no sistema de produção da cana-deaçúcar. In: SIMPÓSIO INTERNACIONAL DE FISIOLOGIA DA CANA-DE-AÇÚCAR, 2000, Piracicaba. Anais... Piracicaba: STAB, 2000. 10p. (CD-ROM).

CASTRO, P.R.C. et al. Ação comparada de ethrel, fuzilade e roundup, em duas épocas de aplicação, na maturação e produtividade da cana-de-açúcar, variedade SP 70-1143. Revista de Agricultura Piracicaba, v.77, p.23-38, 2002.

CESNIK, R.; MIOCQUE, J. Melhoramento da cana-de-açúcar. Brasília, DF: Embrapa Informação Tecnológica, 2004. 307p.

DEUBER, R. Florescimento e maturação da cana-de-açúcar. In: SEMINÁRIO DE TECNOLOGIA AGRONÔMICA, 3. Anais... Piracicaba: Copersucar, nov., 1986. p.587-590.

DEUBER, R. Maturação da cana-de-açúcar na região sudeste do Brasil. In: SEMINÁRIO DE TECNOLOGIA AGRONÔMICA, 4. Anais... Piracicaba: Copersucar, nov., 1988. p.31-40.

DUKE, S. O.; BAERSON, S. R.; RIMANDO, A. M. Herbicides: Glyphosate. In: PLIMMER, J. R.; GAMMON, D. W.; RASGSDALE, N. N.(Eds.) Encyclopedia of Agrochemicals. New York: John Wiley \& Sons, 2003. Disponível em:

<http://www.mrw.interscience.wiley.com/eoa/articles/agr119/frame.html>

FERNANDES, A.C. Refratômetro de campo. Boletim Técnico Copersucar, São Paulo, v.19, p.5-12, 1982.

FERNANDES, A.J. Manual da cana-de-açúcar. Piracicaba: Livroceres, 1984. p. 108-109.

FERNANDES, G.A. Efeito da época de aplicação de inibidores de florescimento na canade-açúcar: aspectos econômicos. 1997. 40 f. Trabalho de Conclusão de Curso (Graduação em Agronomia) - Faculdade de Agronomia “Dr. Francisco Maeda", Ituverava, 1997. 
GALLI, A. J. B. Roundup como maturador de cana-de-açúcar. A melhor opção para flexibilizar o manejo de corte. In: SEMINÁRIO ROUNDUP EFEITO MATURADOR, 1., Anais... Guarujá 1993, p. 18-23.

GERA, P.J.S. Resultados da aplicação de ethephon em cana-de-açúcar (Saccharum spp), nas usinas da Região de Ribeirão Preto. Ituverava (SP). 1994. 41f. Monografia (Graduação em Engenharia Agronômica) Faculdade de Agronomia "Dr. Francisco Maeda", Fundação Educacional de Ituverava, Ituverava.

JULIEN, M.H.R. Testing ripeners: problems and prospects. In: CONGRESS OF INTERNACIONAL SOCIETY OF SUGAR CANE THECNOLOGISTS, 16, 1977, São Paulo. Proceedings... São Paulo: International Society of Sugar Cane Thecnologists, v.2, p.1971-1809, 1977.

LAVANHOLI, M. das G.D.P. et al. Aplicação de ethephon e imazapyr em cana-de-açúcar em diferentes épocas e sua influência no florescimento, acidez do caldo e teores de açúcares nos colmos - variedade SP 70-1143. Revista STAB, v.20, p.42-45, 2002.

LEGENDRE, B.L.; FINGER, C.K. Response of sugarcane varieties to the chemical ripener glyphosate. Proc. Plant Growth Regulator Soc. v.14, p.479-484, 1987.

LEITE, G.H.P. Maturação induzida, alterações fisiológicas, produtividade e qualidade tecnológica da cana-de-açúcar (Saccharum officinarum L.). 2005, 141f. Dissertação (Mestrado em Produção Vegetal) - Faculdade de Ciências Agronômicas - UNESP, Botucatu.

MARTINS, A.C. Avaliação dos efeitos da aplicação aérea de ethephon em áreas comerciais de cana-de-açúcar (Saccharum spp). 1993. 46f. Trabalho de Conclusão de Curso (Graduação em Agronomia) - Faculdade de Ciências Agrárias e Veterinárias UNESP, Jaboticabal.

MORAIS NETO, J. Maturadores e reguladores vegetais na cultura da cana-de-açúcar. In: SEGATO, S.V. et al. (Org.). Atualização em produção de cana-de-açúcar. Piracicaba: CP2, 2006. p.307-318.

MUTTON, M.A. Modo de ação do sal de isopropilamina de $\mathrm{N}$-(fosfonometil) glicina (glifosate) e efeito maturador na cana-de-açúcar. In: SEMINÁRIO ROUNDUP EFEITO MATURADOR, 1., 1993, Guarujá. Anais... Guarujá, 1993. p.9-17.

NASCIMENTO, R. do.; GHELLER, A.C.A. Resultados da aplicação de maturadores vegetais em cana-de-açúcar, variedades RB72454 e RB835486 na região de Araras, SP. 1998. Disponível em: <http://www.propg.ufscar.br/publica/4jc/ixcic/UFSCar/Agrarias/879nascimento.htm>. Acesso em: 21 mar. 2009.

NICKELL, L.G. Plant growth regulating chemicals. Chicago: CRC Press, 1988, v.1/2., $256 \mathrm{p}$.

PATREZZE, A. Efeito do glifosate como maturador químico da cana-de-açúcar, nas características tecnológicas do caldo, na microbiologia e no rendimento do processo fermentativo. 1994. 52 f. Monografia (Trabalho de graduação em Agronomia) - Faculdade de Ciências Agrárias e Veterinárias, Universidade Estadual Paulista, Jaboticabal, 1994. 
PONTIN, J.C. Avaliação de maturadores vegetais na cana-de-açúcar. Álcool \& Açúcar, v.77, p.16-18, 1994.

PROJETO Canasat revela aumento na área plantada com cana-de-açúcar no Brasil.

2008. Disponível em: <http://www.mundogeo.com.br/noticias

diarias.php?id_noticia=12247>. Acesso em: 21. jan. 2009.

RIBEIRO NETO, A. Ácido giberélico e ethephon em cana-planta: efeitos sobre os parâmetros biométricos, produtivos e tecnológicos. 2002.48f. Trabalho de Conclusão de Curso. (Graduação em Agronomia). Faculdade de "Dr. Francisco Maeda". Fundação Educacional de Ituverava.

ROMERO, E. et al. Características y beneficios de la maduración química de la caña de azúcar de Tucumán. Tucumán: EEAOC, 1997. (Avance agroindustrial, 68).

SALATA, J.C.; FERREIRA, L.J. Estudo da interferência do florescimento nas qualidades agroindustriais de algumas variedades de cana-de-açúcar. Brasil Açucareiro, v.88, p.19-24, 1977.

SANT'ANNA, L. A. C. Influência da aplicação de maturadores químicos, sobre as características químico-tecnológicas da cana-de-açúcar (Saccharum spp, var. SP 701143). 1991. 95 f. Monografia (Trabalho de Graduação em Agronomia) - Faculdade de Ciências Agrárias e Veterinárias, Universidade Estadual Paulista, Jaboticabal.

SILVA, M.A. et al. Uso de reguladores de crescimento como potencializadores do perfilhamento e da produtividade em cana-soca. Bragantia, Campinas, v.66, n.4, p.545-552, 2007

SUBIROS, J.F. Efecto de la aplicación glifosato como madurador en tres cultivares de caña de azúcar. Turrialba, San Jose, v.40, n.4, p.527-534, 1990.

STUPIELLO, J.P. Qualidade da cana-de-açúcar para a fabricação de açúcar e álcool. Açúcar e Álcool, v.2, p.28-32, 1982.

UNICA: cana-de-açúcar. Disponível em: 〈www.unica.com.br〉. Acesso em: 22. out. 2005.

VIANA, R.S et al. Maturadores químicos na cana-de-açúcar (Saccharum spp) aplicados em final de safra. Revista de biologia e ciências da terra. v.7, n.2, p.100-107, 2007.

ZILLO, H. Acompanhamento e comparação dos parâmetros tecnológicos com índices de maturação da cana-de-açúcar (var. SP80-1816) submetida à aplicação de maturadores químicos. 2003. Trabalho de Conclusão de Curso. (Graduação em Agronomia) - Faculdade de Ciências Agrárias e Veterinárias, Universidade Estadual Paulista, Jaboticabal. 
